\title{
Safo - Fr. 1 e Fr. 31
}

C. Leonardo B. Antunes

FFLCH-USP

leo.antunes@uol.com.br

ABSTRACT

In this article, we analyse the structure of two poems by Sappho (Fr. 1 and Fr. 31), for which we present a poetic translation. It is followed by a commentary on stylistic aspects of the poems and the way they were recreated (or not) in the translation.

KEYWORDS: Greek; lyric poetry; translation; poetics; Sappho.

\section{Introdução}

Pound dizia que a poesia é um centauro. Nela, "a faculdade intelectiva e aclaradora que articula as palavras deve movimentar-se e saltar juntamente com as faculdades energéticas, sensitivas, musicais".

Há, nessa afirmação, um fundamento importante, a meu ver, para todos aqueles que desejam fazer tradução poética, ou simplesmente apreciar poesia: a noção de que tanto forma quanto sentido precisam caminhar juntos, uma vez que a forma evidencia, define e altera o sentido; e o sentido, ou a pluralidade de sentidos possíveis, por outro lado, corresponde à validação existencial da forma, à sua raison d'être.

O encanto da poesia viria, então, da apreciação conjunta de forma e conteúdo; do entendimento do sentido potencializado pela magia da forma; da beleza da forma dignificada pelo valor do sentido.

A proposta de tradução com que trabalho parte do princípio exposto acima, ou seja, de traduzir poesia com uma preocupação tanto pela forma quanto pelo conteúdo. Esse, obviamente, não é o resultado sempre alcançado, uma vez que a prática sempre fica aquém da expectativa da teoria, mas é o ideal pelo qual procuro sempre me orientar.

Neste artigo, apresento a tradução poética de dois poemas de Safo, frutos de minha dissertação de mestrado, ${ }^{2}$ seguidos de um comentário a respeito de como foram compensados ou imitados na tradução os recursos formais empregados nos poemas gregos, os quais seguem a edição de Campbell. ${ }^{3}$ Os poemas traduzidos possuem marcações em negrito para as sílabas tônicas e sub-tônicas delimitadas no padrão métrico escolhido, o qual se explica no próximo tópico, que introduz ambos os poemas.

\footnotetext{
${ }^{1}$ Cf. Pound, E. A arte da poesia. São Paulo: Cultrix, 1976, p. 70.

${ }^{2}$ Cf. Antunes, C. L. B. Ritmo e sonoridade na poesia grega antiga. Uma tradução comentada de 23 poemas. São Paulo: FFLCH-USP, 2009, p. 92-102 (dissertação inédita de mestrado em Letras Clássicas). ${ }^{3}$ Cf. Campbell, D. A. Greek lyric I. Cambridge/ London: Harvard University Press, 2001.
} 


\section{nuntius antiquus}

\section{Estrofe sáfica}

Os dois poemas de Safo presentes neste artigo seguem um mesmo esquema métrico, comumente denominado estrofe sáfica, que recebeu este nome por ter sido o padrão métrico que notabilizou a poetisa na Antiguidade. Copiada por poetas posteriores, como Catulo (11 e 51) e Horácio (Carmen Saeculare), a estrofe sáfica se caracteriza por possuir três versos sequenciais de mesma conformação, a saber, um metron trocaico, um pé dáctilo e novamente um metron trocaico, seguidos por um quarto verso de menor extensão, que se estrutura na forma de um pé dactílico e úm pé trocaico com anceps na última posição, como pode ser observado no esquema abaixo:

$$
\begin{array}{lll}
-u-x & -u u & -u-x \| \\
-u-x & -u u & -u-x \| \\
-u-x & -u u & -u-x \| \\
-u u & -x \| &
\end{array}
$$

Como exemplo prático, tomemos a primeira estrofe do fragmento 31 de Safo, a fim de analisarmos sua estrutura métrica:

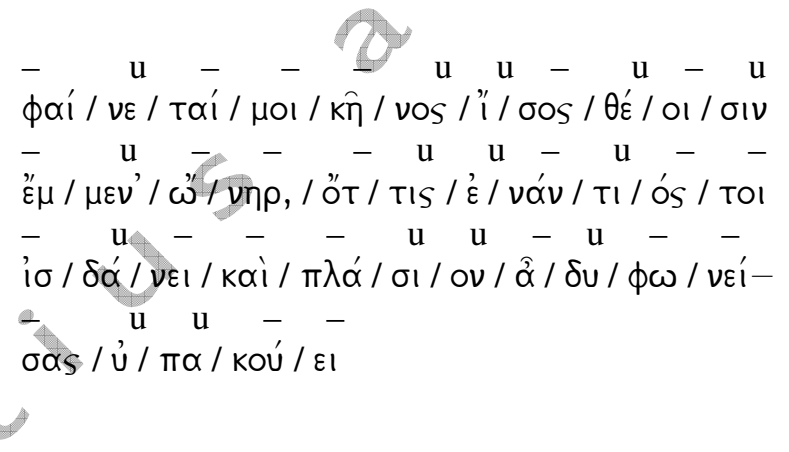

O esquema, seguido rigorosamente, cria um ritmo descendente, por conta da exclusividade de troqueus e dáctilos, que pode ser mais ou menos truncado dependendo das posições livres serem ou não preenchidas por sílabas longas.

Para a tradução, tentou-se seguir o esquema métrico com certa fidelidade, ainda que tomando algumas licenças, para não comprometer as informações e demais efeitos do poema em demasia.

A primeira das liberdades tomada foi a de permitir versos cataléticos, de modo que a última posição, a do anceps, nem sempre estará preenchida, ainda que se tenha evitado isso tanto quanto possível.

A segunda das licenças usadas diz respeito à ordenação das palavras nos versos. Muitas vezes foi preciso mover vocábulos de um verso para outro, além de usar 
traduções menos literais, a fim de preservar tanto o ritmo quanto a sonoridade suave do original.

Para ilustrar de forma prática como o esquema métrico foi empregado no processo de tradução, observemos o exemplo abaixo, um trecho escandido do fragmento trinta e um de Safo:

$$
\begin{aligned}
& \begin{array}{llllllllll}
\mathbf{1} & 2 & \mathbf{3} & 4 & \mathbf{5} & 6 & 7 & \mathbf{8} & 9 & \mathbf{1 0}
\end{array} \\
& \text { E / le / me / pa / re / ce / ser / par / dos / deu / ses, } \\
& \begin{array}{llllllllll}
\mathbf{1} & 2 & \mathbf{3} & 4 & \mathbf{5} & 6 & 7 & \mathbf{8} & 9 & \mathbf{1 0}
\end{array} \\
& \text { O ho / mem / que / se / sen / ta / pe / ran / te / ti } \\
& \begin{array}{llllllllll}
\mathbf{1} & 2 & \mathbf{3} & 4 & \mathbf{5} & 6 & 7 & \mathbf{8} & 9 & \mathbf{1 0}
\end{array} \\
& \text { E / se in / cli / na / per / to / pra ou / vir / tua / do / ce } \\
& \begin{array}{llll}
1 & 2 & 3 & 4
\end{array} \\
& \text { Voz / e / teu / ri / so }
\end{aligned}
$$

Apesar de os primeiros versos de cada estrofe serem de dez sílabas em português, eles obedecem a um ritmo pouco usual em nossa língua e reproduzem, com um bom grau de fidelidade, a sequência de marcação rítmica do original.

De modo geral, empregou-se um metro composto pela justaposição de dois troqueus, um dáctilo e mais dois troqueus, com a possibilidade do último ser catalético. A única exceção em que o anceps da quarta posição acabou sendo ocupado por uma sílaba forte foi o seguinte:

$\begin{array}{llllllllll}1 & 2 & \mathbf{3} & \mathbf{4} & \mathbf{5} & 6 & 7 & \mathbf{8} & 9 & \mathbf{1 0}\end{array}$

Fil / ha / de / Zeus / que ur / de / em / ga / nos, / pe / ço-

Como resultado, esse verso da Ode a Afrodite se estruturou pela sequência de um troqueu, um espondeu, um dáctilo e dois troqueus, sendo o único nos dois poemas de Safo do corpus a usar de modo diferente o anceps da quarta posição.

\section{Safo - Phainetai moi (Fr. 31)}

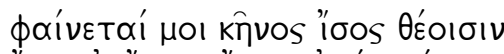

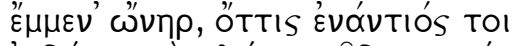

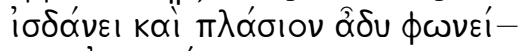

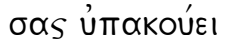

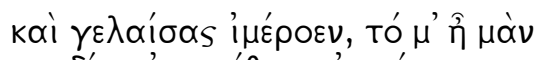




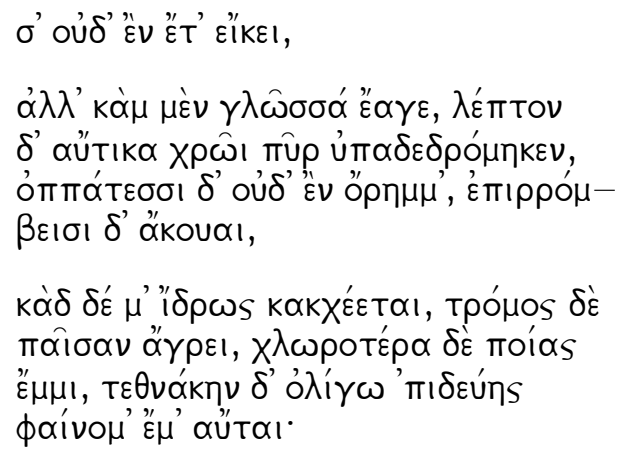

Ele me parece ser par dos deuses, O homem que se senta perante ti E se inclina perto pra ouvir tua doce Voz e teu riso

Pleno de desejo. Ah, isso, sim, Faz meu coração 'stremecer no peito. Pois tão logo vejo teu rosto, a voz Perco de todo.

Parte-se-me a língua. Um fogo leve Me percorre inteira por sob a pele. Com os olhos nada mais vejo. Zumbem Alto os ouvidos.

Verto-me em suor. Um tremor me toma Por completo. Mais do que a relva estou Verde e para a morte não falta muito É o que parece.

O texto do fragmento 31 de Safo comumente apresenta quatro estrofes de quatro versos cada. No entanto, algumas edições consideram também a existência de um último verso solto. Pelo fato de que essas quatro estrofes possuem uma unidade bemdelimitada e também por conta desse verso final aparentemente não acrescentar muito, ele foi deixado de fora. ${ }^{4}$

O poema foi composto com quatro estrofes de mesmo padrão métrico, de modo a conferir-lhe uma unidade que, de outra forma, talvez não existisse, devido ao fato de que a maior parte do texto é usada para descrever a falha do funcionamento de diversas funções e sentidos do corpo do eu-lírico. Ademais, outro fator que colabora imensamente para criar um conjunto coeso e uma unidade sólida para o poema é a

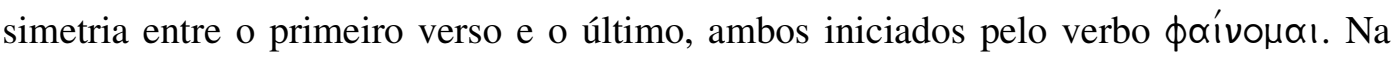

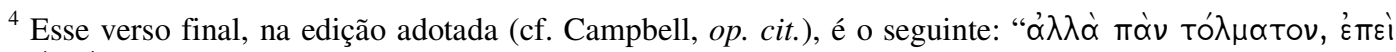

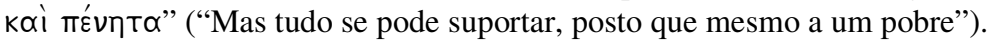


primeira ocasião, ele se refere ao homem que está perto da amada do eu-lírico e, na segunda, ao próprio eu-lírico. Tentou-se manter esse efeito até certo ponto, mas não foi possível deixar os dois verbos no início de verso na tradução, uma vez que ele não se encaixa no esquema métrico.

O primeiro verso do texto grego, ainda mais do que os restantes, tem uma

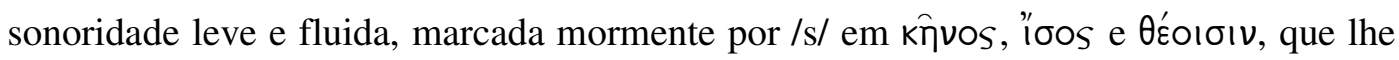
conferem uma qualidade quase diáfana, fazendo com que o verso seja pronunciado sem dificuldade. Na tradução, tentou-se manter essa sonoridade, com uma sequência de /s/ em "parece", "ser", “dos" e "deuses".

O segundo verso da segunda estrofe, por outro lado, tem um andamento mais truncado e, ao mesmo tempo, mais delineado por conta da concentração de sons de /t/

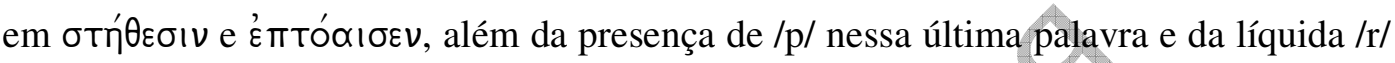
em $k \propto \rho \delta i \propto \nu$, cujo próprio som intensifica a ideia da instabilidade enunciada no verso. Esse último efeito foi recriado na tradução com o vocábulo "estremecer", que, junto de “peito”, completa o campo sonoro existente em grego com certa fidelidade.

Desse verso em diante, há uma longa descrição de como os vários sentidos do corpo do eu-lírico se confundem e deixam de funcionar normalmente quando na presença de sua amada. Durante essa descrição, há uma forte presença de enjambements, que fazem com que o texto adquira um andamento rápido, quase alucinado, que só encontra uma pausa definitiva no final da quarta estrofe com o prenúncio da morte. Na tradução, tentou-se, tanto quanto possível, manter essa característica do texto original, preservando o cavalgamento.

Por fim, nessa mesma passagem, há a ocorrência de um polissíndeto, pela repetição contínua da partícula $\delta \varepsilon$. Esse artifício é bastante comum no grego antigo, a ponto de praticamente não se sobressair em relação à estrutura do texto. Por esse motivo, ele foi traduzido por orações simples e sem coordenação, criando um assíndeto no texto em português.

\section{Safo - “Ode a Afrodite” (Fr. 1)}

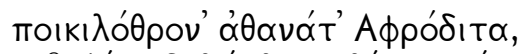

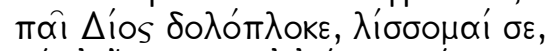

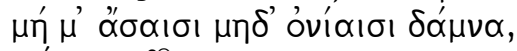

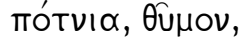




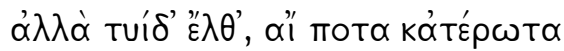

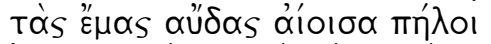

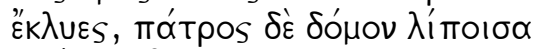

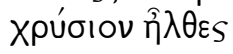

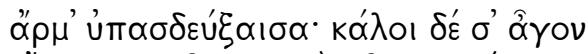

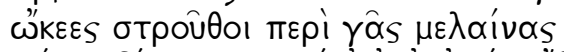

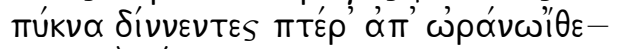

pos $\delta ı \grave{\alpha} \mu \dot{\varepsilon} \sigma \sigma \omega$,

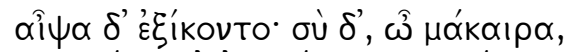

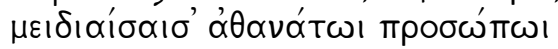

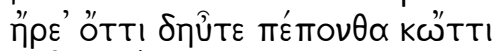

$\delta \eta \cup ิ T \varepsilon$ кó $\lambda \eta \mu \mu \mathrm{I}$,

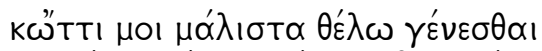

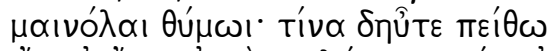

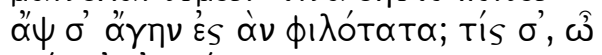
$\psi \alpha_{\alpha}^{\prime} \phi^{\prime}, \alpha_{\alpha} \delta ı n^{\prime} \varepsilon 1 ;$

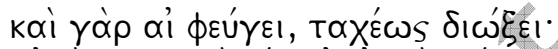

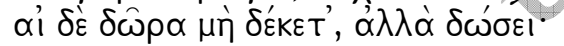

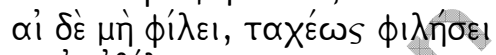

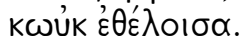

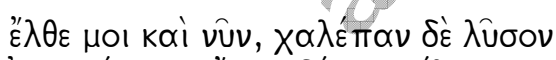

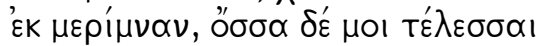

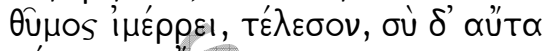

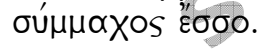

Afrodite eterna de etéreo trono,

Filha de Zeus que urde enganos, peço-

Te: com mágoa e náusea não domines,

Dona, minh'alma,

Mas pra cá descende se alguma vez,

Tendo a voz me ouvido de muito longe, Escutaste e a áurea casa pátria,

Vindo, deixaste em

Carro atrelado. Formosas aves

Ágeis te levavam por sobre a terra

Negra, densas asas no céu vibrando em

Meio ao ar.

Logo aqui chegaram e tu, ditosa,

Em teu rosto eterno um sorriso abrindo, Quis saber a causa de minha angústia,

A ordem do apelo, 


\section{nuntius antiquus}

O que eu mais queria que me passasse

De ânimo imprudente. "Agora quem

Devo persuadir para ti. Quem, Safo,

Faz com que sofras?

Se ora foge, logo te irá no encalço. Se rejeita os dotes, não tarda a dá-los. Se não te ama, logo ela vai te amar Contra a vontade."

Vem-me agora, pois, desfazer essa árdua 25 Aflição. Perfaz-me o que minha alma Sonha ver perfeito, e sê tu mesma Minha aliada.

Na Ode a Afrodite de Safo, o eu-lírico faz um pedido de ajuda à deusa, seguindo a ordem padrão de uma prece, a saber: a enunciação do nome e dos epítetos da entidade a quem se está dirigindo, a lembrança de alguma relação preexistente entre o mortal e o deus, culminando, por fim, no pedido propriamente dito. Como um paralelo ilustrativo, pode-se lembrar o pedido, a Apolo, feito por Crises no início da Ilíada. A partir do verso trinta e sete do primeiro canto, o velho sacerdote troiano inicia uma prece ao deus,

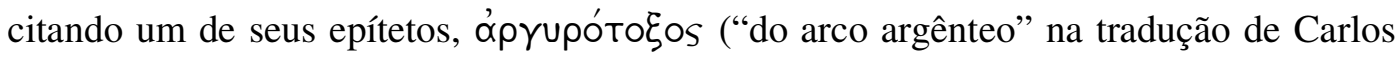
Alberto Nunes), além de elencar algumas de suas áreas de atuação. Em seguida, ele afirma já ter construído templos magníficos e feito sacrifícios em honra ao deus. Somente depois disso, ele faz o pedido de intervenção de Apolo numa vingança sobre os Aqueus por não lhe devolverem a filha.

Deixando de lado o exemplo da épica e partindo para a análise estrutural do poema de Safo, pode-se dizer que ele foi construído pela sucessão de quadras feitas num mesmo padrão métrico. Nas três primeiras, encontram-se a invocação da deusa e o início da lembrança de vezes passadas em que ela veio ter com o eu-lírico. A quarta quadra marca a metade do poema no momento em que, na lembrança, a deusa chega até a mortal. Na quinta e na sexta quadra, pode-se observar a recordação de um diálogo em que a deusa se mostrou favorável ao eu-lírico. Por fim, na sétima e última quadra, há o pedido por auxílio divino.

O primeiro verso dessa ode de Safo, considerado por Pound ${ }^{5}$ um dos mais belos já criados, apresentou as mais sérias dificuldades dentre as encontradas no processo de

${ }^{5}$ Cf. Pound, op. cit., p. 18. 
tradução do poema. A primeira delas, como ocorrido no outro poema de Safo presente neste trabalho, foi a de encontrar uma palavra em português para traduzir moıkí̀os, uma vez que a tradução literal, "variegado", dificilmente condiz com a sonoridade buscada. Limitando ainda mais as opções, havia o metro enxuto escolhido para a

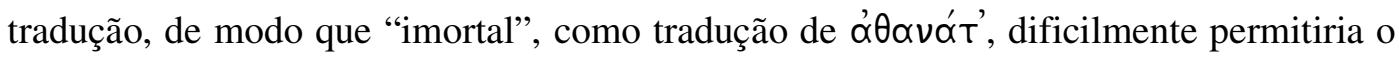
uso de um adjetivo adequado e mais extenso para substituir "variegado". Por esse motivo, no lugar de "imortal" foi empregado "eterna", cujo sentido, para os gregos, era semelhante quando usado em relação aos deuses, como se pode observar na Teogonia de Hesíodo. ${ }^{6}$ Tendo livrado algum espaço, dessa forma, foi possível escolher um vocábulo mais longo e cuja sonoridade fosse forte o bastante para emular o efeito que se tem em grego pela sucessão de sons de /t/ até culminar em $\alpha \dot{\theta} \alpha \nu \alpha$ '’, para em seguida o som quase que deslizar para "AfrÒdita". Em português, dois dos pontos máximos do verso são a sílaba tônica de "etéreo" e a de "eterna", as quais se intensificam pela sequência de sons de /t/ ao longo do verso, que prosségue até terminar em "trono", tendo começado com o próprio nome da deusa. Teria sido mais interessante manter "Afrodite" no final do verso, mas não foi de todo possível, de modo que a melhor solução encontrada foi deixar o termo em destaque no início do verso, abrindo o poema.

$\mathrm{Na}$ tradução do segundo verso do poema, houve um problema de ordem intertextual, por conta da lembrança da bela tradução que J. A. A. Torrano fez desse

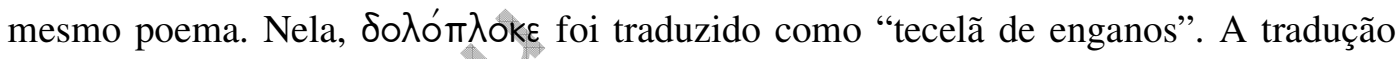
desse vocábulo sempre me pareceu tão adequada que levou certo tempo até conseguir desvencilhar-me dela e perceber que havia outras opções que se encaixariam melhor no metro empregado. À versão de Torrano, esse trabalho ainda deve crédito pelo uso do verbo "perfazer" para traduzir as duas ocasiões em que derivados de $\tau \varepsilon \lambda \varepsilon^{\prime} \omega$ aparecem, além de, certamente, inspiração em outras ocasiões do poema.

Do segundo para o terceiro verso da tradução, preferiu-se separar "peço-“ de "te", tanto por ser um recurso empregado por Safo em outros poemas, quanto por uma necessidade métrica, pois de outra forma teria sido difícil fazer com que o restante do verso se encaixasse no padrão métrico adotado.

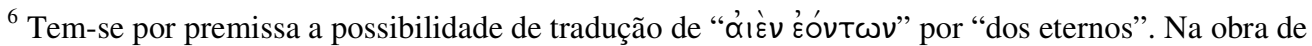

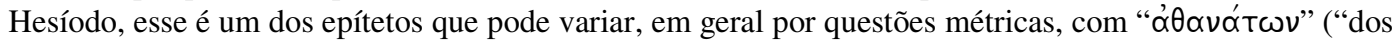
imortais") para referir-se aos deuses. Por exemplo, pode-se verificar o verso vinte e um da Teogonia; ocasião em que eles, aliás, aparecem juntos.
} 


\section{nuntius antiquus}

No terceiro verso da sexta quadra, foi preciso adicionar um "ela", para deixar claro que o objeto de desejo do eu-lírico é uma mulher, o que, em grego, está implícito na terminação do particípio '̇ $\theta \dot{\varepsilon} \lambda \circ ı \sigma \alpha$, que se encontra no verso seguinte, o qual teve uma tradução pouco literal por necessidades métricas. Mais literalmente, lê-se "mesmo não querendo".

\section{Referências}

ANTUNES, C. L. B. Ritmo e sonoridade na poesia grega antiga. Uma tradução comentada de 23 poemas. São Paulo: FFLCH-USP, 2009 (dissertação inédita de mestrado em Letras Clássicas).

BAILLY, A. Dictionnaire Grec-Français. Paris: Chantraine, 1950.

CAMPBELL, D. A. Greek lyric I. Cambridge/ London: Harvard University Press, 2001.

LIDDEL, H. G.; SCOTT, R. A Greek-English Lexicon. Oxford: University Press, 1996.

POUND, E. A arte da poesia. São Paulo: Cultrix, 1976.

WEST, M. L. Introduction to Greek Metre. Oxford: Clarendon Press, 1987. 